\title{
Implementation of Hospital Information System in Research Institute of Ophthalmology, (Ministry of Higher Education and Scientific Research), Giza, Egypt - A situation analysis study.
}

\author{
${ }^{1}$ Manal H. Abuelela ${ }^{2}$ Nahed F. Elwazeer ${ }^{3}$ Shereif S. Karawya \\ ${ }^{1}$ Public Health Department, ${ }^{2}$ Pediatrics Unit Research Institute of Ophthalmology, ${ }^{3}$ Medical \\ Retina Unit, Ophthalmology Department, Research Institute of Ophthalmology, Giza, Egypt. \\ Submitted:11-05-2020 Revised:20-07-2020 \\ accepted:24-07-2020
}

\begin{abstract}
Overall, the implementation of digital health information system in general and Electronic medical record (EMR) can improve quality of care, reduce cost in managing care environment and improve provider efficiency. EMR systems have the potential to provide clinical data essential for research. Objective:The main objective of this study was to develop a full automation of Research Institute of Ophthalmology(RIO) hospital through the detailed Hospital Management Information System implementation plan, and to build an information repository that includes all the information of patients attending RIO to be used in the purposes of scientific research and decision-making support.Method: The study relied on a comprehensive and detailed analysis method (Situation analysis) by combining observation, inquiry and personal interviews for direct access to information and building a system capable of addressing the problems and difficulties facing the Institute. Results: A large database containing the necessary information for each patient was established, that facilitated retrieval of essential data for patient care and conduction of research, reduction in paper costs, effort and time was also achieved and it insured protection and safety system for patient's medical information. Conclusion:Digital transformation is $\mathrm{s}$ a bright spot in the history of the Research Institute of Ophthalmology, which provides researchers with a huge information repository of eye diseases in Egypt through patients attending the institute's hospital. This project also represents a nucleus that can facilitate the hospital's connection to a future government health insurance project, which is expected to link the medical service to the patient's national number.
\end{abstract}

Keywords: Hospital Information System, Ophthalmology Institute, Research.

Corresponding author:Manal Hassan AbuelelaEmail:Manal_elela@yahoo.com/m.abuelela@rio.edu.eg

\section{Introduction}

Hospital Information System is an integrated information system designed to manage the administrative, financial and medical aspects of the hospital. ${ }^{1-13}$ In 2006 , the World Health Organization highlighted the importance of the electronic medical record from being the cornerstone of any computerized health system, as it represents a central point in which many channels of information related to providing health care to the patient are inaugurated. ${ }^{14-16}$ Research Institute of Ophthalmology is considered a unique center in the field of ophthalmology in Egypt and Middle East that provides advanced ophthalmologic care for patient's allover Egypt and other countries with continuous improvement in medical 
education, training and research. The Idea of establishing the Research Institute of Ophthalmology (RIO) was due to Prof. Dr. Abdel-Mohsen Soliman, Professor of Ophthalmology, Ain Shams University "the initiator and the donor of the Institute's land $\left(4480 \mathrm{~m}^{2}\right)$ overlooking River Nile." In February 1989, according to the Presidential Decree No 40, RIO was established as an independent research institute affiliated to the Ministry of Scientific Research in Egypt, combines both clinical and research services and dedicated to ophthalmic research \& management of eye diseases.On Sunday April 3, 1990, the institute was officially opened.On February 25, 1990, RIO organizational structure was approved by the Egyptian Central Agency for Organization and Administration.

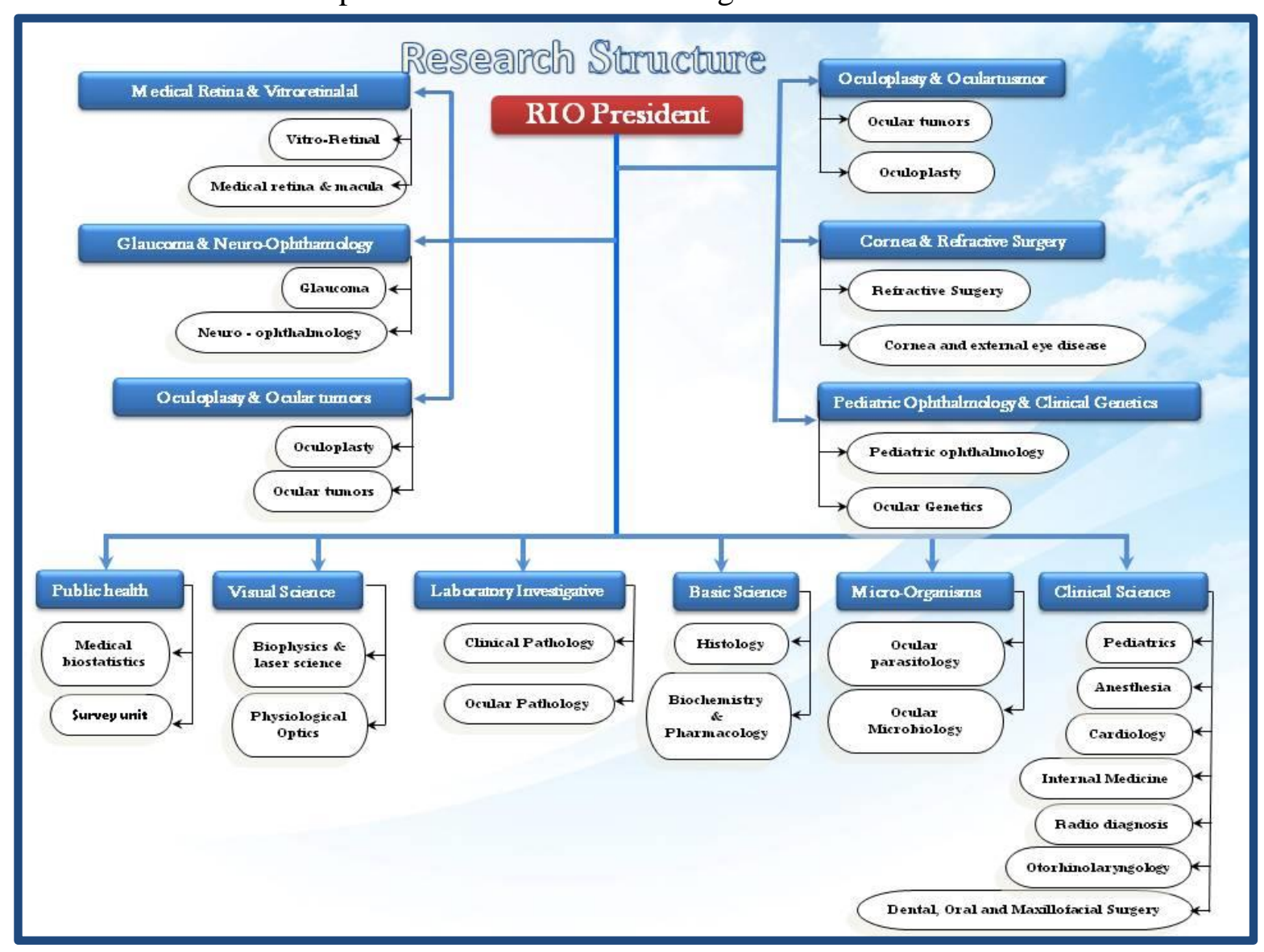

Figure 1: The Research Structure of Research institute of Ophthalmology

RIO Buildings (consists of 3 buildings) : Administrative Building - (4 Flours), Hospital building - (8 Flours), Conference Hall.

RIO Hospital: RIO hospital has 85 beds for patients with inner section. Around 80000 patients/ year attend different RIO clinics and about 7000 patients' undergone surgeries.Outpatient Clinics: Ophthalmology, E.N.T, Cardio-vascular, Internal medicine, Dental
Specialized Clinics: Cornea, Cataract, Glaucoma, Macula \& medical retina, Surgical retina, Laser treatment (Argon \&Yag), Refractive and Lasik, Ocular tumors \&Oculopalsty, Ophthalmic genetics, Pediatric ophthalmology Investigative Clinics: Visual field, Corneal research, ERG, VEP, EOG, Fundus fluorescein angiography, OCT, Ocular ultrasonography \& Biometry, Corneal 
topography, SLO, Pentacam, Specular microscope, ORA, ECHO, Abdominal ultrasonography, X-ray

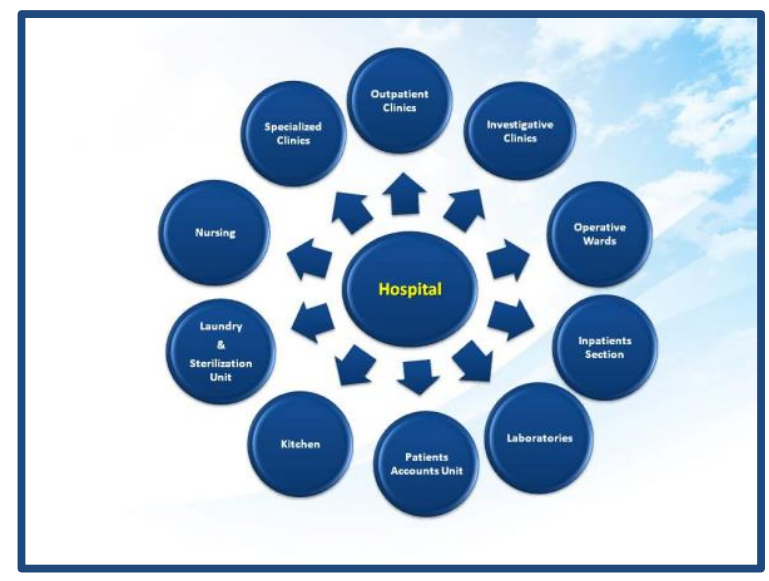

Figure 2: Hospital Structure of Research Institute of Ophthalmology

Operative Wards: Includes 8 operating rooms equipped with modern devices, surgical equipment, supplied with T.V circuits, connected to the internet.

Laboratories: PCR, Clinical pathology, Histology, Parasitology, Microbiology, Molecular genetics, Physiological optics, Biophysics and laser science, Pathology \&electro-microscopy, Biochemistry, pharmacology, and RIO Stem Cell Lab, which is established according to Clean Room Technology. It provides the suitable environment to perform Stem Cell Research.

RIO Animal House:It provides pure breeds of experimental animals required for the institute's researches or outside researchers. The chamber is equipped with operations unit.

The grand plan of Research Institute of Ophthalmologyis to providean excellent ophthalmologic medical services, raiseresearch skills and to ensure the best organization and control of hospital resources and build an information repository that includes all the information about patients attending Research Institute of Ophthalmology, depending on the computer with all its advanced capabilities; from storing information, processing and transferring data through information networks and modern means of communication for use in the purposes of scientific research and decision support to optimize the capabilities of the institute in setting the necessary programs to combat the most common eye diseases and directing research and medical projects to the community and groups most affected by the disease.

The main objective of this study was full automation of RIO Hospital through the detailed Hospital Management Information System (HMIS) implementation plan. And building an information repository that includes all the information of patients attending the Research Institute of Ophthalmology (RIO), to be used in the purposes of scientific research and decision-making support.

\section{Method}

The study was based on a comprehensive and detailed analysis methodology (Situation analysis) by combining the observation inquiry and personal interviews for direct access to the information to build a system capable of addressing the problems and difficulties facing the Institute.A cross sectional facility based study wasconducted along two weeks among 27staff members RIO's doctors and nurses with response rate $57.4 \%$. The total sample size was calculated to be 47 participantscalculated by Statcalc version 7, based on the fact that $44 \%$ of Egyptians own personal computers, ${ }^{17}$ absolute precision was assumed to be 0.05 and confidence level 
95\%, taking into consideration the involvement of different categories who were actively included in the new system; including junior specialized medical staff, nursing officers, Pharmacists/medical Laboratory (total number were54).

Figure 3: The Project Plan

In spite of the availability of the appropriate infrastructure in

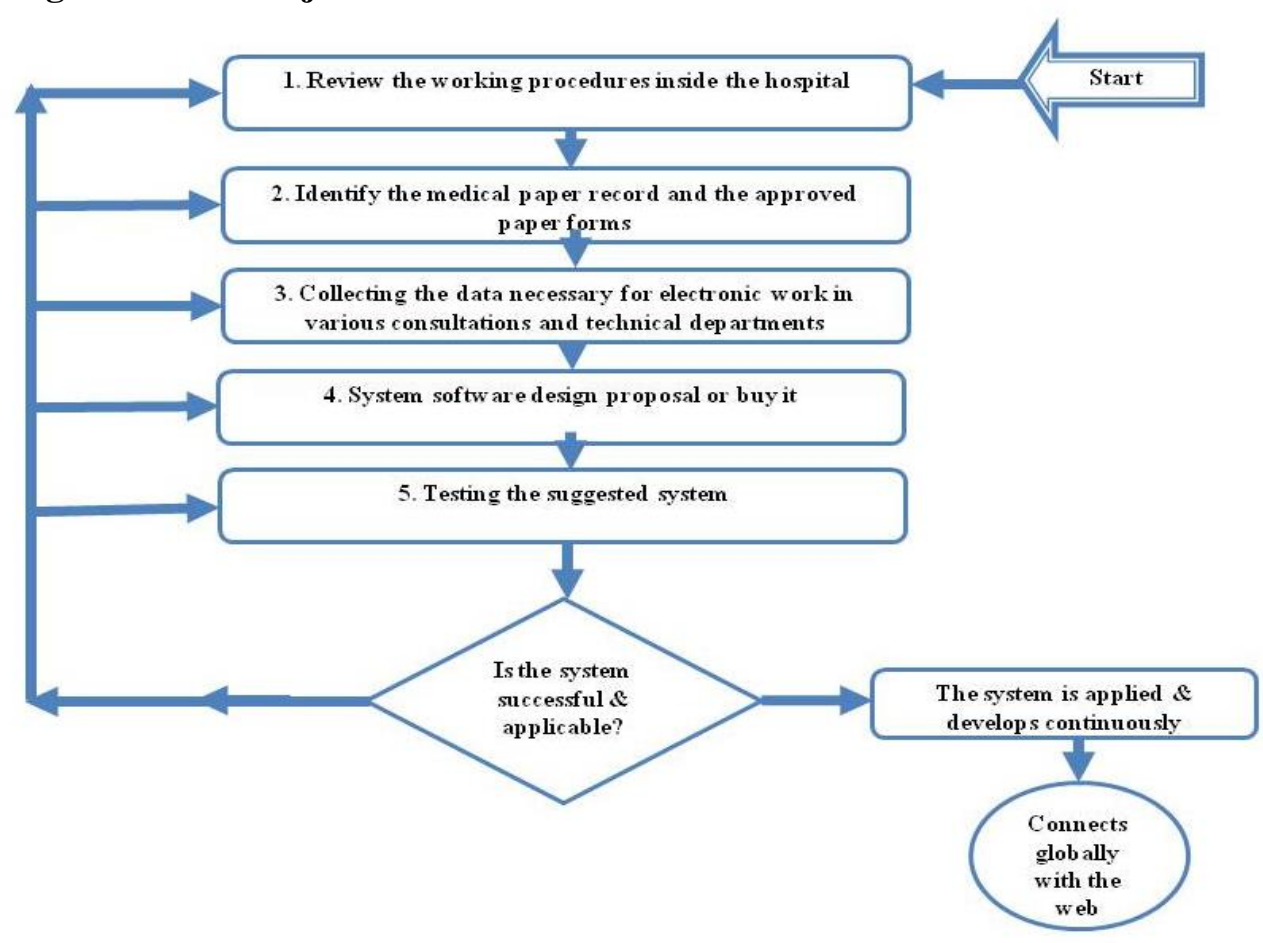

The published questionnaire by Zaky\&Alshammaa, 2013 was used.The questionnaire was first explained by the researcher team and it was selfadministrated by each participant. This questionnaire included two parts; the first was ten questions that must be answered yes or no, while the second part included five open questions.

\section{Data Analysis}

All completed questionnaire forms were entered into the computer, Statistical Package of Social Science Software program (SPSS), version 21 to be statistically analyzed. Descriptive statistics such as frequency and percentage were used for data summarization. Diagrams and figures were used to illustrate simple information.
Research Institute of Ophthalmology, the administrative benefit from the technical progress did not reach the desired aspirations, as it was found that there were many negatives and complaints that were received from patients and doctors working in the hospital related to the optimal use of time and errors that might occur in obtaining private information about patients and their previous medical history, due to the adoption of traditional paperwork.

2. Analysis of the pre automation system (Current situation):Information was collected on the old system, analyzed to identify and define problems to deal with, on selecting the new system and making the necessary twinning. Data were collected through personal interviews with: 
General Director of the hospital, Reception staff, Nursing supervisors, Doctors The administrative structure of the institute working in the hospital. and the hospital (Figure1, 2, 4).

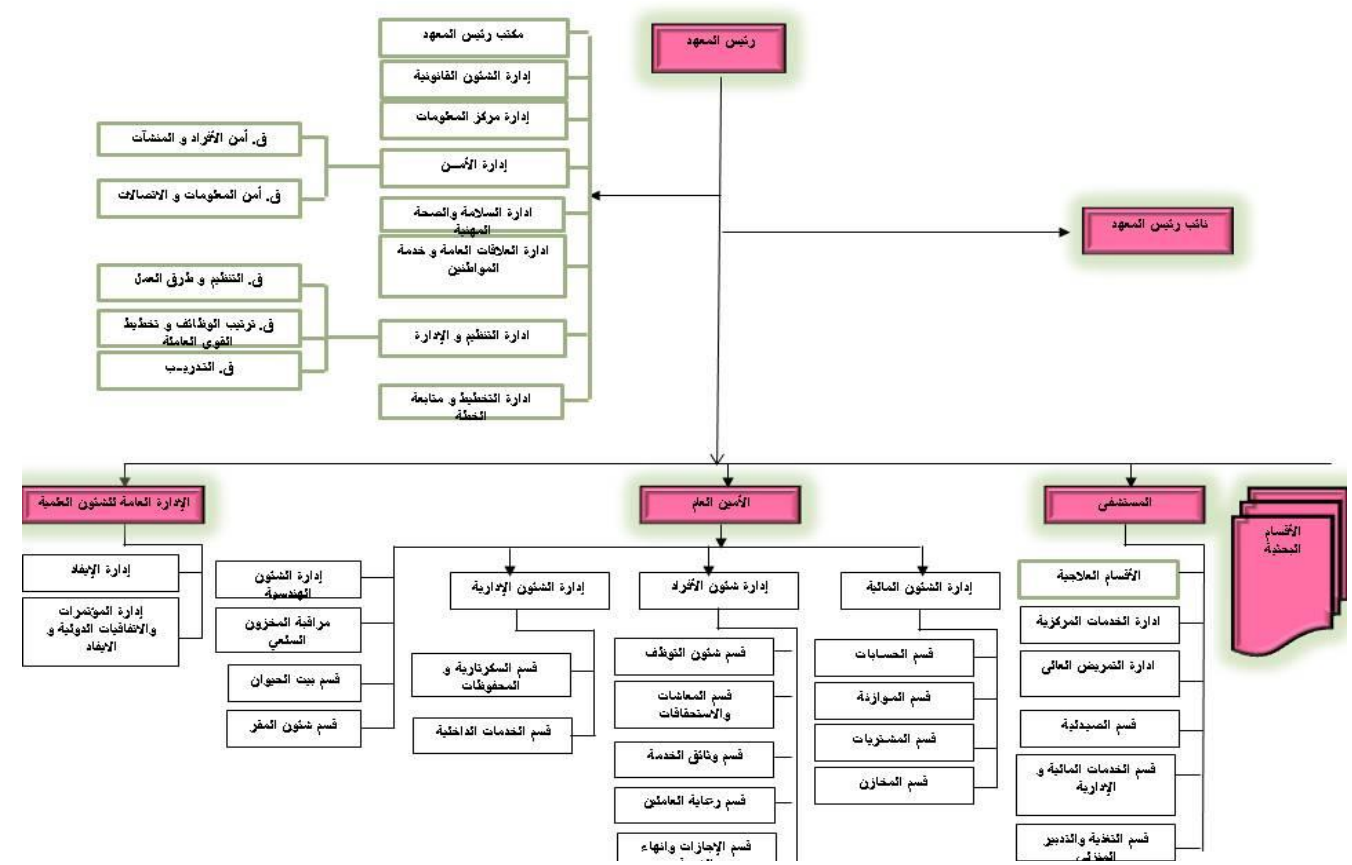

Figure 4: Administrative Structure of Research Institute of Ophthalmology

The general manager of the hospital was responsible for the administrative and technical supervision of all departments and clinics according to the accepted regulations and laws, and also responsible for submitting a periodic report on the hospital's performance to the president of the institute.These reports were extracted through tedious documentation of daily work atthe hospital.

Most clinical and basic research data was stored in disparate and separate systems, and it was difficult for clinicians and researchers to access and share these data. Furthermore, inefficient workflow management in clinics and research laboratories created many obstacles to medical/ clinical research, decision-making and assessment of outcomes.

Problem analysis:we deduced that RIO traditional manual systemhad major problems that could be summarized as follows: - a. Lack of appropriate information at the right time to make the right decision, it was very difficult to retrieve information and find specific information such as knowing the history of a disease for a particular patient, as the user must view multiple records, that led to waste of time and effort on searching for specific information between thousands of data or call specific patient data based on specific medical or administrative data.

b. Lack of immediate storage of information, as the information resulting from the various transactions took time and efforts to be stored in the right place.

c. The lack of a quick update, it was difficult to make various changes to the information, such as patient details.

d. Account was error-prone, manual calculations were prone to error and timeconsuming, which might result in incorrect information. For example, calculating a patient's bill based on different treatments. 
e. The difficulty of preparing accurate and rapid reports, as it was difficult to collect information from different records,

f. The large number of patient files, which required the provision of large areas to save these files. Single patient may had several records. Moreover, patient could obtain his medical record keeping it at home.

g. The inability to share information between hospital departments.

h. The process of searching files took a lot of time and effort.

i. Traditional files were more prone to damage and theft than electronic files.

j. Making backups needed a lot of time, effort and money.

When analyzing the results of the questionnaire, we found some positive and negative points, which was important to work to strengthen the positive points and address the negative points before and during the implementation of the electronic system. About $92.6 \%$ of the participants had a personal computer while only $63 \%$ could work on it. But only $51.9 \%$ had experience in using software and the Internet.

It was found that $66.7 \%$ of the participants expressed their dissatisfaction with the traditional paper system and $92.6 \%$ expected that the implementation of the electronic system will achieve a better performance for the hospital. And 85\% supported the implementation of the electronic system. This was considered one of the strong points that helped the electronic system to succeed. Therefore, we found that the participating team split into two groups $85 \%$ with the application while $15 \%$ against the implementation of the electronic system. Consequently, we had to train supporters and find out the reasons for refusal to address them when implementing the electronic system. and therefore a difficulty to know the general situation inside the hospital.

The most important problems facing workers such as doctors, nursing and administrators were difficulty in communication between hospital departments, slow procedures, difficulty in the retrieval of patient data and data loss, making effort and time in the paper system and repeated work steps.

The main characteristics that respondents requested focused on ease of use, appropriate training, quality of services, and patient privacy.

\section{Solutions Proposed by Authors}

First: The development of the traditional system with shortening of unnecessary steps, but the problems of storage, retrieval and slow procedures will remain, so this solution was not useful.

Second: Partial electronic construction that works in parallel with the traditional system, but the problem of storage will remain and is also considered costly as two systems will be worked on simultaneously. So, this solution was also useless.

Third: Building an integrated computer system may be less expensive, but the lack of scientific cadres in preparing, designing and implementing this system will lead to spending a lot of time and may not pay off in terms of integration and compatibility between the components of the system and lead to the loss of money as well. So this solution had a risk factor.

Fourth: Purchasing a readymade system and to be chosen to suit the hospital work environment with the commitment of the supplied company to make the necessary alignment and to be purchased in batches that end up meeting the hospital needs to solve all the previous problems.

\section{The chosen solution by Authors}


Hospital computing had been chosen, as this system (HIS) provided an online storage / update and retrieval service, so less paperwork was required, and information could be retrieved easily without searching here and there in the logs. The electronic medical record system was a system to automate all operations inside the hospital in addition to archiving and facilitating access to them with minimal time and effort. And follow-up in terms of the safety of procedures, completing information and making the
Immediate storage of information. 7. Ease of operation

The implementation plan.

The implementation plan included ten steps;determination of the teamwork, preparing the place, determining the necessary devices and equipment, creating a request for proposal, acceptance and evaluation, evaluation of offers, justification, compatibility, system testing, training.

First: Determination of the teamwork. The project team consisted of:

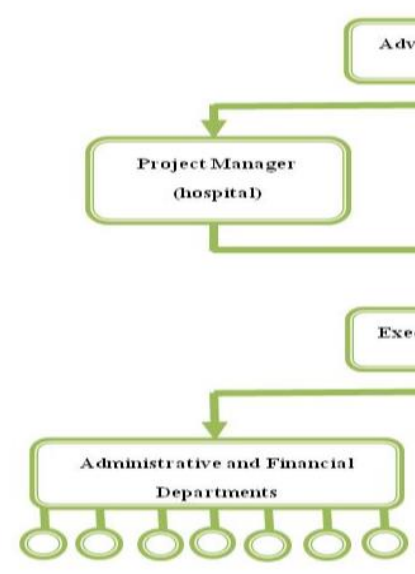

right decision in a timely manner.

The desired goals of the chosen system were: (1)well Planning and organizing work, where data could be stored correctly in data stores that would help in retrieving information as well as storing it.(2)Accuracy; all operations were performed correctly, and all information was accurate (3) Reliability; increase the reliability of the system where storage would be suitable for information. (4)No duplication of information anywhere, this would ensure the economical use of storage space and consistency in the stored data. (5)Immediate information retrieval: the main goal of the system was to provide a fast and efficient information retrieval. 6 .

Second: Preparing the place: 1.Preparation of the information center to include the system servers and the router network to accommodate the new

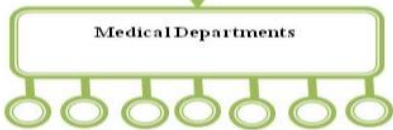

The general manager of the hospital, who played the role of technical guidance. The project manager played the role of coordinator. Secretary General of the institute as well as the chief financial officer was responsible for the budget. The training supervisor was for training who was a specialist with previous experience in information technology. The medical supervisor was for medical support.

A map of the organizational and executive structure of the project has been developed by forming an advisory committee responsible for the reviews and approvals and an executive committee responsible for implementing all steps of the plan.

automated system. 2. Ventilation has been adjusted to provide a high cooling effect. 3. Connecting servers with alternative generators to the hospital. 4. Purchasing a 
special server for the program and purchasing a data storage unit for the new system.

Third: Determining the necessary devices and equipment: Specify the number and type of hardware needed and purchase it to create a fully integrated system (servers, computers, scanners, printers, communication lines, and internet and data storage).

Fourth: Creating a request for proposals: Putting the technical specifications brochure to contain the latest information technology in this field to improve the services provided by the institute to the international levels, including electronic diagnostics for patients and the possibility of entering more than one consultant from outside the hospital to express the opinion of the same also carried out according to what was stated in the brochure of terms and patient, the immediate warning to the doctor and the pharmacy in case of allocating a drug that contradicts the patient's health condition and other international medical standards to obtain a global electronic system for hospital management. A general practice was introduced in the Office of the Ministry of Scientific Research to purchase, supply, installation and maintenance of hospital management system of the Research Institute of Ophthalmology.

Fifth: Acceptance and evaluation: The foundations of technical evaluation were taken into account in evaluating the group's elements in practice according to Egyptian and international standards. The technical evaluation and acceptance criteria for the technical points system were specifications, and it is explained in the following table:

Table 1: The Technical Evaluation and Acceptance Criteria for the Technical Points System

\begin{tabular}{lc}
\hline \multicolumn{1}{c}{ Evaluation component } & Points \\
\hline Matching the technical specifications and conditions of the Institute & $\mathbf{1 0}$ \\
\hline The demonstration of the actual system & $\mathbf{4 0}$ \\
\hline $\begin{array}{l}\text { Previous work for hospitals using the system and not less than clinical } \\
\text { capacity of 200 beds. }\end{array}$ & $\mathbf{2 0}$ \\
\hline Additional technical features & $\mathbf{1 0}$ \\
\hline $\begin{array}{l}\text { Achieve a balance between ease of use and cover the full needs of the } \\
\text { hospital. }\end{array}$ & $\mathbf{2 0}$ \\
\hline Total & $\mathbf{1 0 0}$ \\
\hline
\end{tabular}

A company that got less than $85 \%$ of the total points was considered technically rejected.

Sixth: Evaluation of offers: The following table shows the technical offers submitted by companies, as well as the technical evaluation corresponding to each item:Five companies bought the specifications booklet, but only two companies submitted their proposals, they were evaluated and the project management team selected Company A as it has the best offer.Seventh: Justification: The management approval was obtained by senior management and the project team to complete the work and adhere to the new 
Table 2: Payment Terms

\section{$\%$}

\section{Payment Terms}

125 Advance payment upon contracting and receipt of the supply order against an approved bank guarantee letter of exchange and unconditional of the same value.

235 A second payment of the total value of the covered sales order six months after receiving the first payment.

340 A final payment after eighteen months from the date of the contract, provided that all work subject to the contract is completed.

Table 3: Technical Offers Submitted by Companies and the Technical Evaluation

\begin{tabular}{|c|c|c|}
\hline Evaluation component & A & B \\
\hline $\begin{array}{l}\text { Matching the technical specifications and conditions of the } \\
\text { Institute } 10\end{array}$ & 9 & 5 \\
\hline The demonstration of the actual system 40 & 38 & 30 \\
\hline $\begin{array}{l}\text { Previous work for hospitals using the system and not less } \\
\text { than clinical capacity of } 200 \text { beds. } 20\end{array}$ & 17 & 12 \\
\hline Additional technical features 10 & 8 & 5 \\
\hline $\begin{array}{l}\text { Achieve a balance between ease of use and cover the full } \\
\text { needs of the hospital. } 20\end{array}$ & 18 & 14 \\
\hline Total & 90 & 66 \\
\hline
\end{tabular}

system and take full responsibility for the success of the implementation and share the responsibility for failure.

Timetable of the project: The project's time range was three years, the project started on January 1, 2016 and ended on December 31, 2018. Table (4) showed the project implementation schedule. 
Table 4: The Project Implementation Schedule

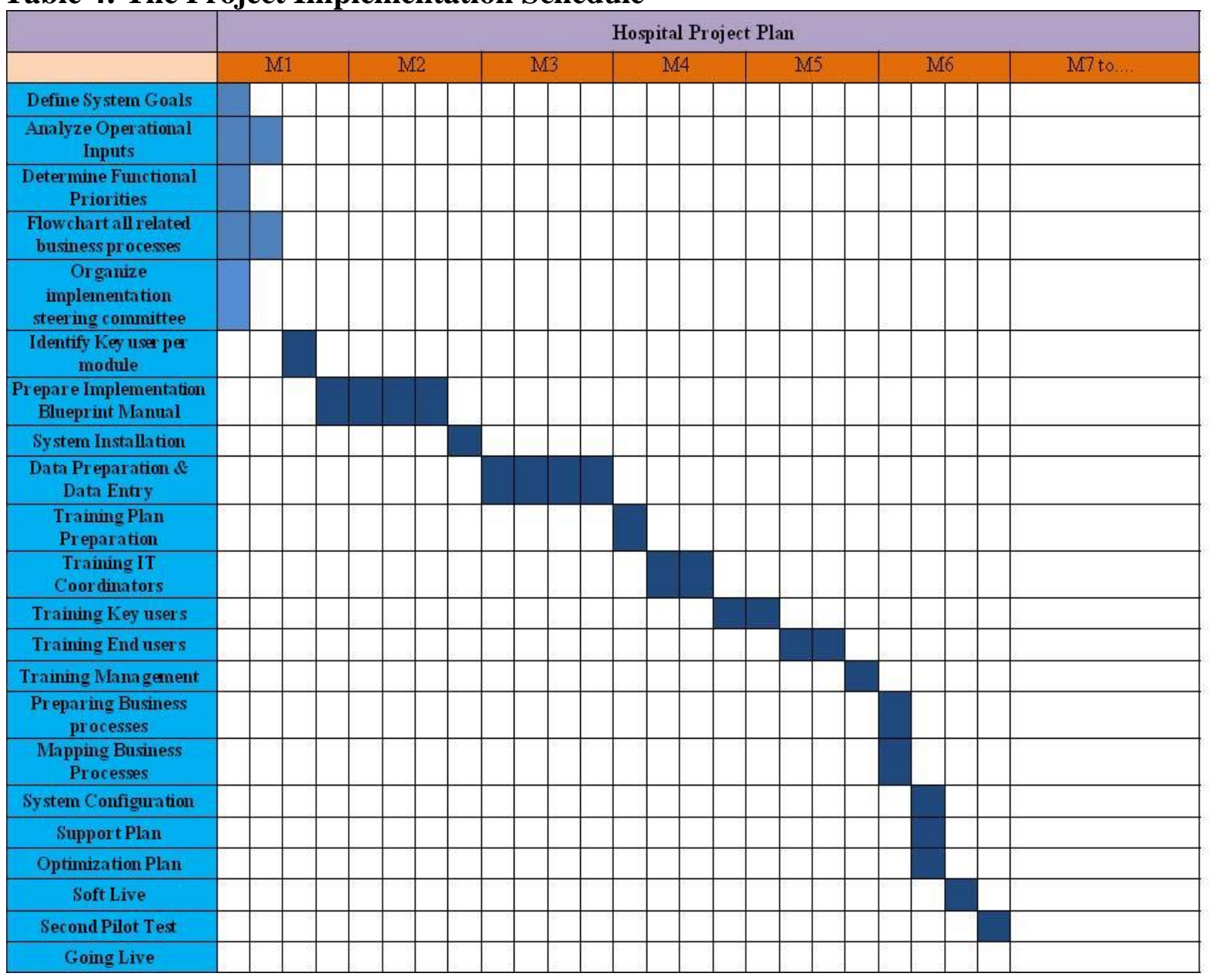

Table 5:SystemCost

\begin{tabular}{|c|c|c|}
\hline 1. Hardware & $\begin{array}{ll}\text { - } & \text { Devices } \\
\text { - } & \text { Supplies }\end{array}$ & 300,000 LE \\
\hline 2. Software & $\begin{array}{l}\text { - } \\
\text { - }\end{array}$ & \multirow[t]{2}{*}{ 1,730,000 LE } \\
\hline 3. Installation & $\begin{array}{l}\text { - Installation } \\
\text { - } \quad \text { Training }\end{array}$ & \\
\hline \multicolumn{2}{|l|}{ Cost of implementation } & 2,030, $000 \mathrm{LE}$ \\
\hline Maintenance & & $\begin{array}{l}350,000 \mathrm{LE} / \text { year after the } \\
\text { end of the warranty period }\end{array}$ \\
\hline
\end{tabular}

Eighth: Compatibility: All applications were adapted to suit the hospital work cycle through several study and analysis sessions to find out everything related to the hospital work cycle in order to set the necessary settings on the system to ensure the success of the hospital work cycle and prepare the patient's workflow in RIO.

Ninth: System testing: System testing was an endless process before installing the system software and extending 
beyond the start date of the live broadcast.

\section{System test stages}

1. System testing on development: It has been performed in the company supplying the system-by-system developers to ensure that all hospital orders and requirements are loaded onto the system with the required specifications.

2. System testing upon installation: It has been performed in the hospital by IT professionals (the supplier company) to ensure that tests are performed and documented by system developers give the same results when IT professionals perform these tests.

3. Job testing within each unit: It has been performed by department managers to ensure that each of them reached the required level.

4. Test integration between modules: The integration of all units was tested as if they were operating in real life.

5. System interaction test with external systems: the new system has been tested with respect to interaction with external systems; hospital suppliers' systems such as pharmaceutical companies, insurance providers, banks and other hospitals.

6. Test and follow-up after the live broadcast: This were a very important and ongoing process after the launch of a new system to ensure that the new system worked effectively and met the standards. Trial operation: The medical registration for a case came to the RIO's hospital and was managed using the new system. Steps from the reality of the system; began from registration to entry and conducting operations to hospital discharge.

Tenth: Training: The training process is divided into three levels and lasted for one month. Level 1: The system developers trained IT professionals during the implementation process to ensure that they meet the standards.Level 2: IT professionals have trained managers to participate in the testing process to provide ideas and support.Level 3: IT professionals have trained each employee on how to use their unit that is related to their job.The training went through three stages:The first stage: an overview of the new system.The second stage: specific procedures and activities for each unitThe third stage: controls, errors and recovery procedures.By the end of the training process:1. a copy of the user manual has been received.2. Training is an ongoing process that does not stop but is checked periodically.3. Members' performance is evaluated and corrected continuously.

\section{Final Operation:}

Real-time workflow at the Eye Diseases Research Institute hospital (Workflow) (Figure 6). 


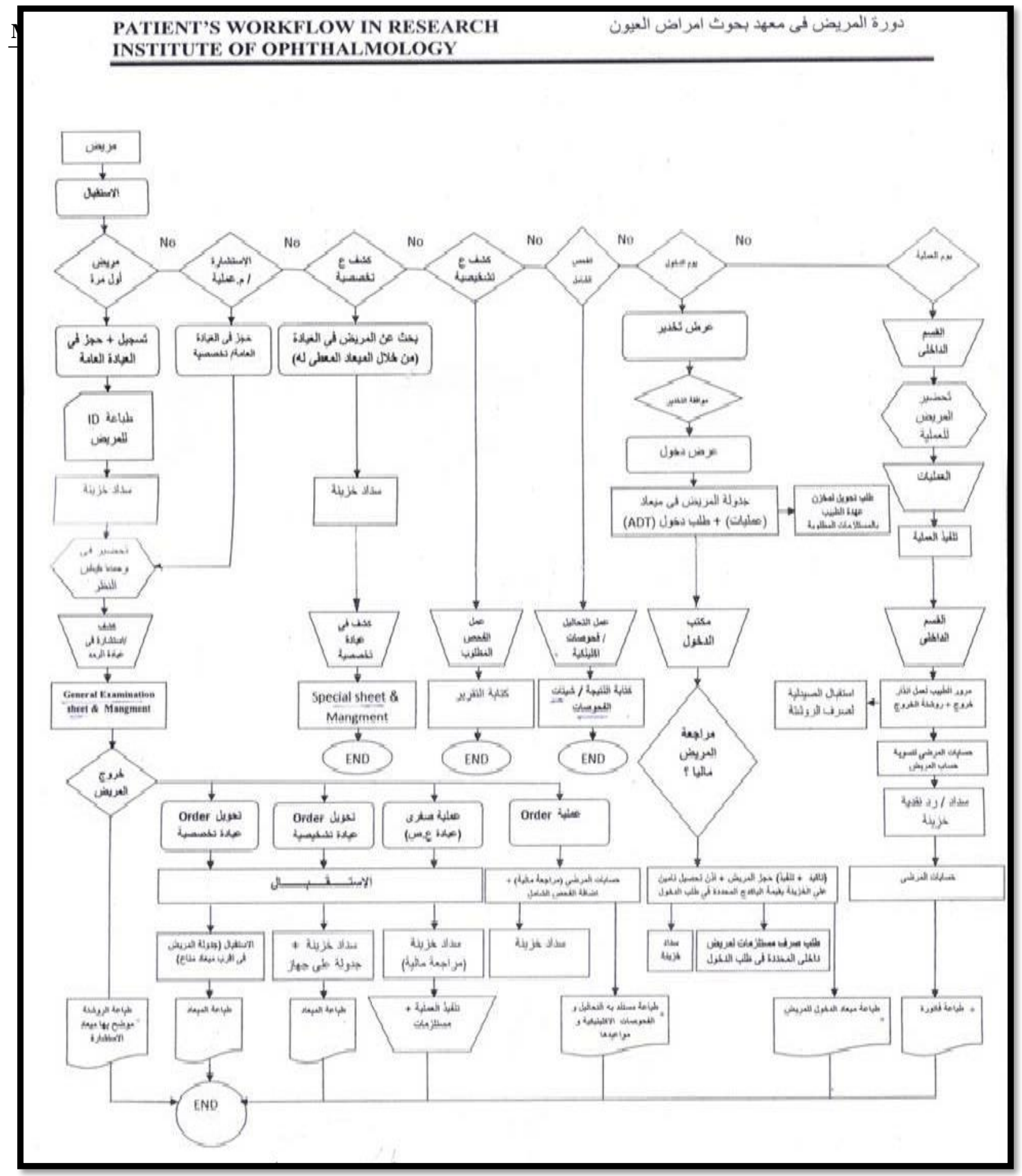

Figure 6: Patient's workflow (system integration) in Research Institute of Ophthalmology 


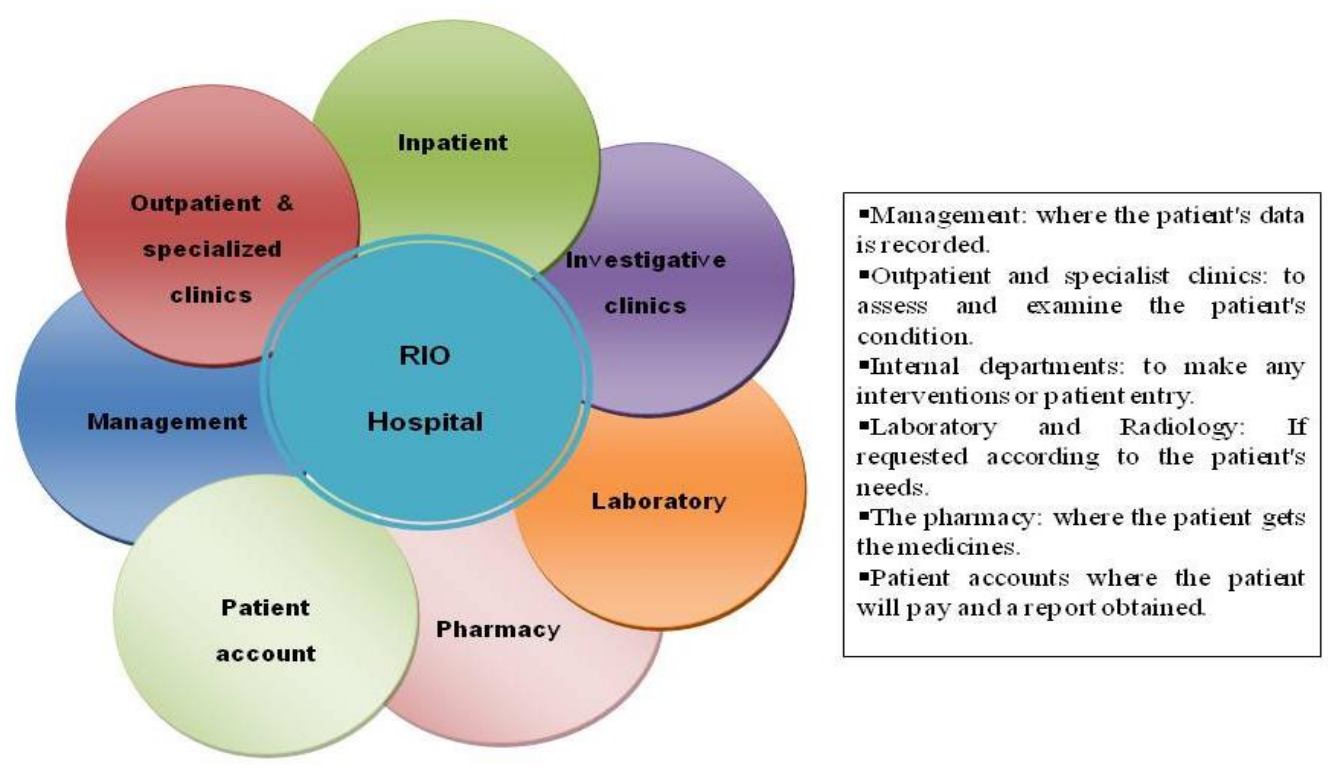

Figure 7: Real-time Hospital Workflow

This process conducted automatically through the new system using data to make the patient's electronic file sent electronically to the different parts in a second.

Figures 8 till figure 24 showed different screenshots which represent several modules of the new automatedRIOhospital information system.

Difficulties and obstacles that we have been faced: 1 . Costs of changing to an electronic system. 2. The lack of technology due to the delay in completing the preparation of the required computers and printers, the delay in the availability of a server with the required facilities, the delay in reviewing and updating the hospital's internal network.3. Lack of technical expertise and computer skills of employees, a lack of network engineers and a computer specialist.4. Resisting change from manual documentation to electronic documentation by doctors, nursing and administrators, which was a major problem, so it took a lot of time to change or modify the behavior and practices of health practitioners at least.5. The small number of active participants in the system-specific settings (postponement and procrastination at times).6. The presence of working medical, nursing and administrative staff not trained in the use of modern technologies, which belong to old generations who did not learn at the beginning of their ages to use modern technologies that hinder the application of such systems, this has led to the existence of two operating systems at the same time the traditional paper system and electronic system, Which led to the inability to follow the information recorded on computer systems, and therefore the information may be inaccurate, and the result was an electronic computer system with information that cannot be used. This strengthened the attitude of the old generation not to invest these systems.

\section{Recommendations}

- It must be taken into account that the application of the health information system requires a long period of time that 
may extend up to five years, and then those responsible for it must have a long life, ignoring the criticism that will be directed to them during the first years of application.

Although the introduction of the entire electronic health records system seemed out of reach at the Research Institute of Ophthalmology, there is no doubt that the future of health information management lies in the automation and automatic transmission of information needed to manage patients at all levels of health care.

- The absence of long-term strategies in health institutions, which may expose these systems to collapse after their installation, as a result of a malfunction that does not have the financial capabilities to repair it, or it is impossible to deal with the companies that sell these systems because of the laws and monotony.

The most important statistics and reports that couldbe delivered regularly out of the automated systemwere:

The RIO's institute hospital is an 87-bed government hospital - specializes in ophthalmology and one-day surgeries. The system that has been implemented and trained upon it operates on a computer network that currently had more than 160 computer units and more than 950 users work on the system.

Table 6: The Most Important Statistics Obtained Easily from The New System at Any Time

\section{RIO's hospital dealing with:}

\begin{tabular}{lll}
\hline - & average number patients attending outpatient clinics & 550 patient/ day \\
\hline - & average number patients attending internal departments & $50-60$ patient/ day \\
\hline - & average number of daily surgeries & $50-60$ surgery/ day \\
\hline - & Public or private contracting agencies. & $>150 \mathrm{report} / \mathrm{month}$ \\
\hline - & Different services (clinical examination, diagnostic & $>63$ agency \\
& operations, dispensing of drugs, etc). & 900 service/ day \\
\hline - & drugs and supplies & 5000 items \\
\hline - & different suppliers & $>60$ items \\
\hline - & average number of medical records (added or updated) & $900 \mathrm{record}$ day \\
\hline - & Doctor's financial dealings & $>200 \mathrm{doctor}$ \\
\hline
\end{tabular}

This huge amount of data.... cannot really be confined to traditional manual methods. Types of reports: A lot of reports could be extracted through the new system such as: Admission form, Referral letter, Exit summary, Vital signs report, Fluid intake and output balance, Medical patient data reports, Outpatient reports, Laboratory reports, Radiology reports, Patient followup reports, Referral reports, Infection Control Reports, Pharmacy content reports, Financial status reports, Patient exit reports, Patient Accounting Reports,
Wages and salary analysis reports, Employee end of service reports.

\section{Conclusion}

We succeeded to implement a new system which is a large database containing the information necessary for each patient, that facilitated the return to the patient's medical history by physicians and facilitated the task of conducting medical research and studies, while ensuring the confidentiality of the patient's medical information through the presence of a 
protection and safety system while specifying the authorities of users.

This project was considered a nucleus that could facilitate linking the hospital with the future government health insurance project, through which it is expected that the medical service will be linked to the patient's national number.

\section{References}

1. Wager K, Lee F, Glaser J (2009), "MANAGING HEALTH CARE INFORMATION SYSTEMS: A Practical Approach for Health Care Management", John Wiley \& Sons, Inc., San Francisco, CA, USA.2ed edition

2. Wei X. (2011), Hospital Information System Management and Security Maintenance, Computer and Communication Engineering School of Weifang University, China. Wu Y (Ed.): ICCIC 2011, Part IV, CCIS 234, pp. 418-421. Springer-Verlag Berlin Heidelberg.

3. Amin IM, Hussein SS, Isa AM, 2011: Assessing User Satisfaction of using Hospital Information System (HIS) in Malaysia; International Conference on Social Science and Humanity IPEDR vol.5 (2011) (C) (2011) IACSIT Press, Singapore.

4. Berg, M. (2001): Implementing information systems in health care organizations: myths and challenges. International Journal of 11.Alyoubi BA, Alsulaimani, TS 2017: The Strategic Role of Electronic Medical Records "Emr" In Supporting Electronic Health System in Saudi Hospitals. IAJPS; 4 (10): 3879-3889

12.USF health online. Benefits of electronic health records. Accessed. [July 2020]. https://www.usfhealthonline.com/resources/he althcare/benefits-of-ehr/

13.Mugo DM, Nzyoka, BMN, Ng'ang'a SM. (2020). Medical Device Integration with Electronic Health Records: A Case Study of University of Nairobi Health Services, Kenya. INTERNATIONAL JOURNAL OF COMPUTERS \& TECHNOLOGY, 20, 14-21. 14. World Health Organization (WHO) (2006), "Health Metrics Network, framework and standards for the development of country
Medical Informatics, 64, 2-3, 143-156. https://doi.org/10.1016/S1386-5056(01)002003

5. Handler T, Holtmeier, R, Metzger, J, Taylor S, Underwood C (2003): HIMSS Electronic Health Record Definitional Model. HIMSS the Source of healthcare Information. www.himss.org

6. Sprague L (2004): Electronic Health Records: How Close? How Far to Go? , national health policy forum, Washington, NHPF Issue Brief; 800: 1-17. www.nhpf.org

7. Fraser HSF, Biondich P, Moodley D, Choi S, Mamlin BW, Szolovits P (2005): implementing electronic medical record systems in developing countries. The Journal of Innovation in Health Informatics; 13:83-95. DOI: 10.14236/jhi.v13i2.585.

8. Adler-Milstein J, Bates DW, 2010: Paperless healthcare: Progress and challenges of an IT-enabled healthcare system. Business Horizons; 53: 119-130.

9. Bedai A (2011): History of Medical Records. http://badai.ahlamountada.com/t385topic.

10.Zaky M. and El-Shammaa M. (2013): System Implantation Plan in Nasser Institute Hospital. Postgraduate healthcare and hospital management diploma gradation project. School of Business - Management Center, the American University in Cairo.

health information systems", First edition, WHO, Geneva.

15.World Health Organization(WHO) (2012), Management of patient information: Trends and challenges in Member States, Global Observatory for e Health series - Volume 6. ISBN 9789241504645

16. Silow-Carroll S, Edwards JN, Rodin D, 2012: Using electronic health records to improve quality and efficiency: the experiences of leading hospitals. Issue Brief (Common Fund); 17:1-40.

17.Badran MF, 2013: "Young People and the Digital Divide in Egypt: An Empirical Study," Working Papers 813, Economic Research Forum, revised Dec 2013.https://doi.org/10.24297/ijct.v20i.8480 


\section{Appendix}

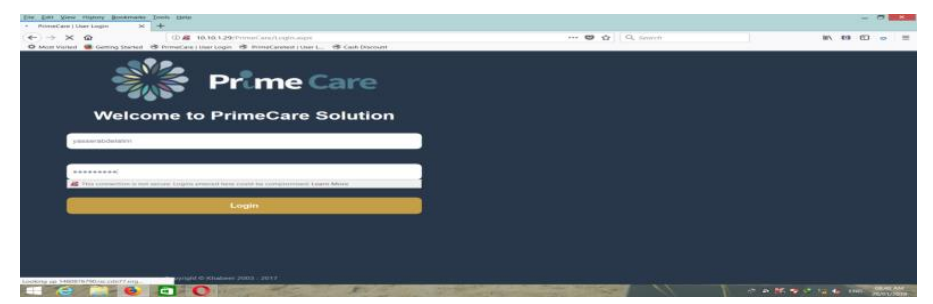

Figure 8: Screenshotof security and control system

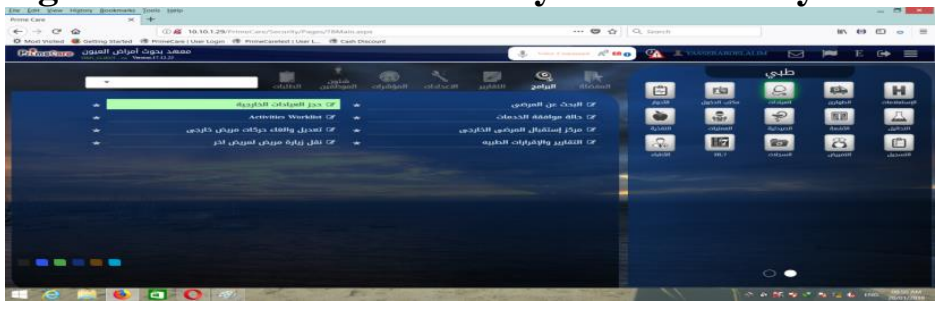

Figure 9: Screenshot of Outpatients screen

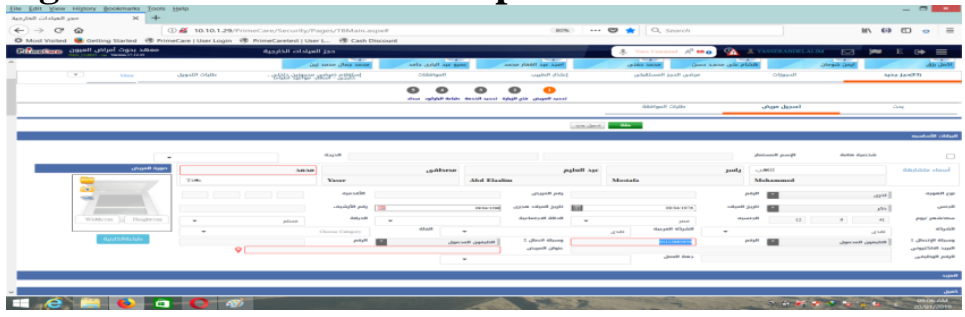

Figure 10: Screenshot of patient registration system screen

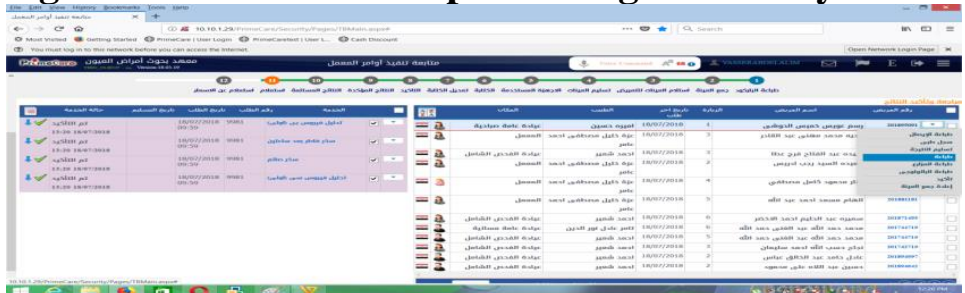

Figure 11: Screenshot of follow up laboratory requests

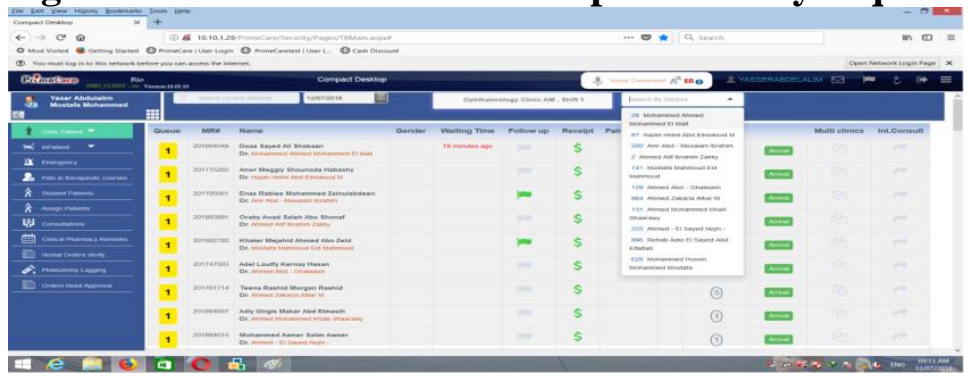

Figure 12: Screenshot of doctor desktop 


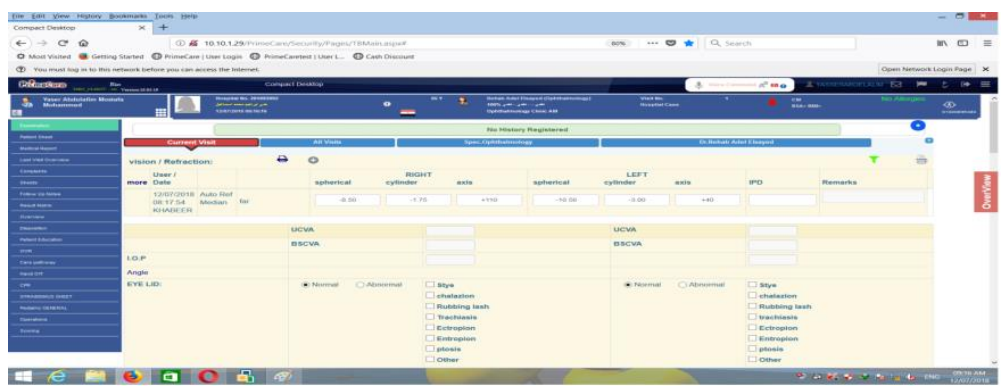

\section{Figure 13: Screenshot of Generel ophthalmolgy Sheet}

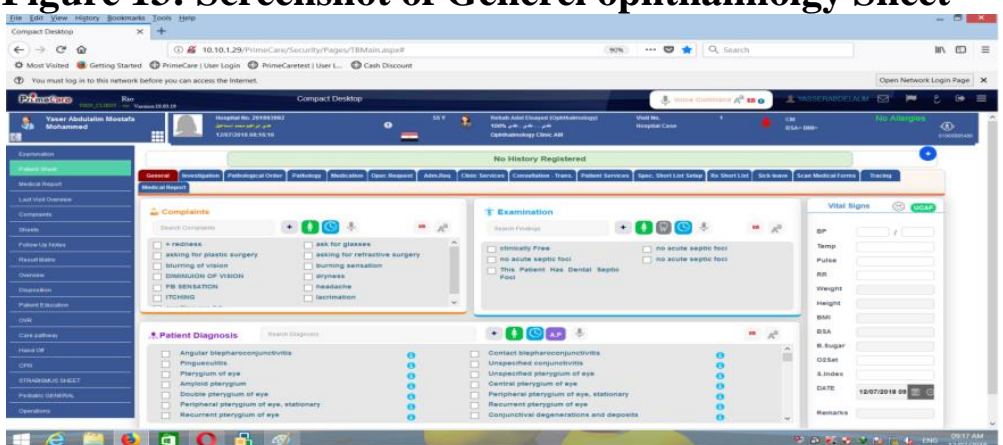

\section{Figure 14: Screenshot of registration screen for patient medical history}

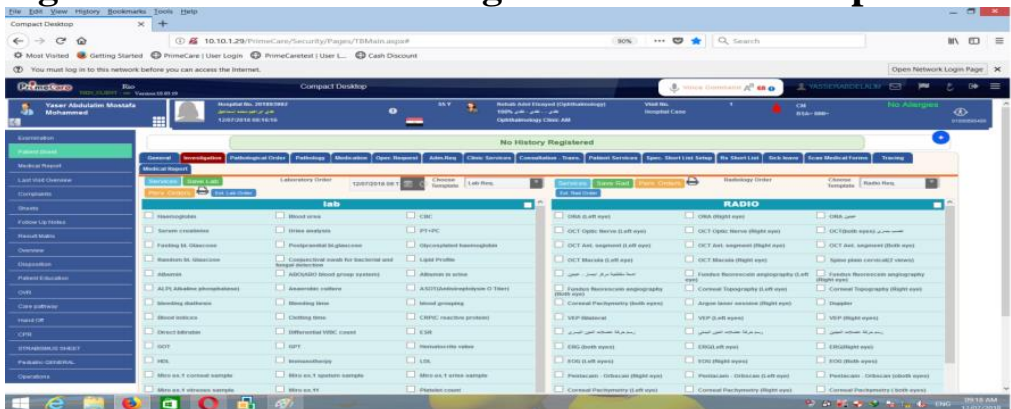

Figure 15: Selection of radiation and laboratory tests necessary for the patient

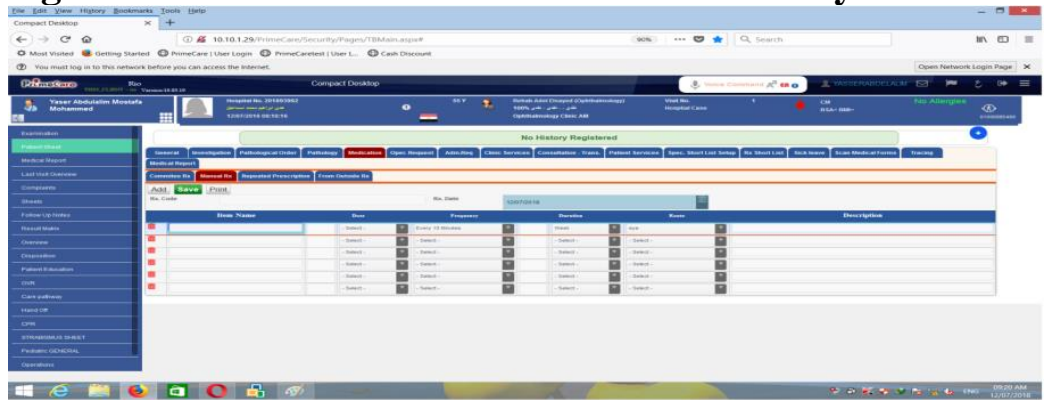

Figure 16: Screenshot of writing prescription for the patient 


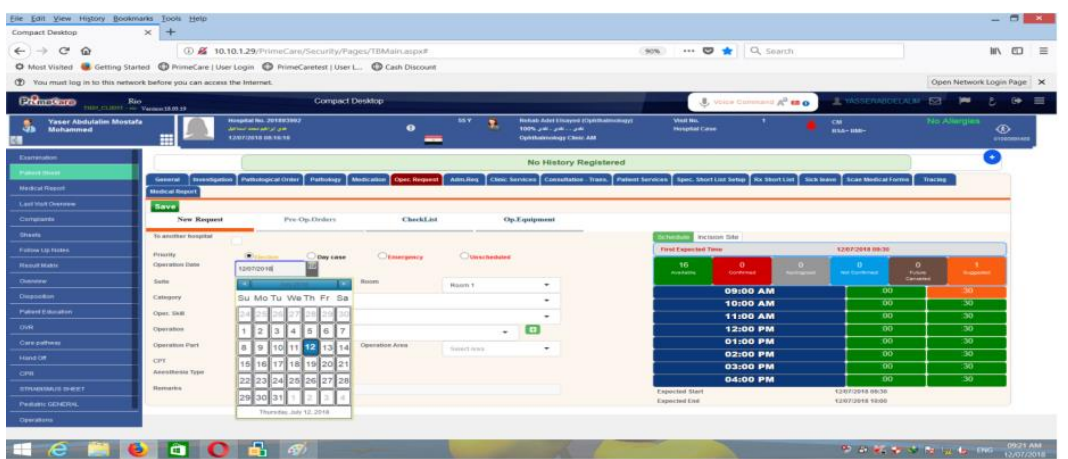

Figure 17: Screenshot of operation request of a patient

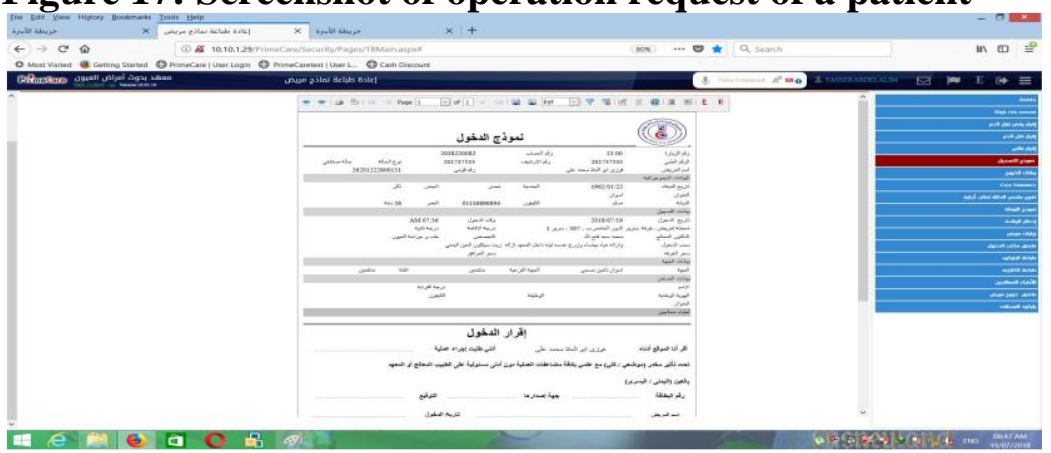

Figure 18: Screenshot of printable admission form of a patient

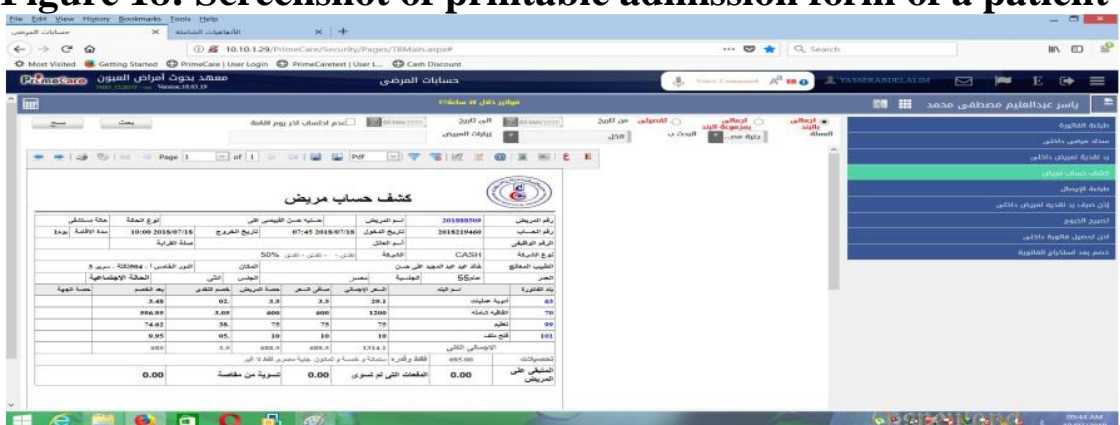

Figure 19: Screenshot of patient statement

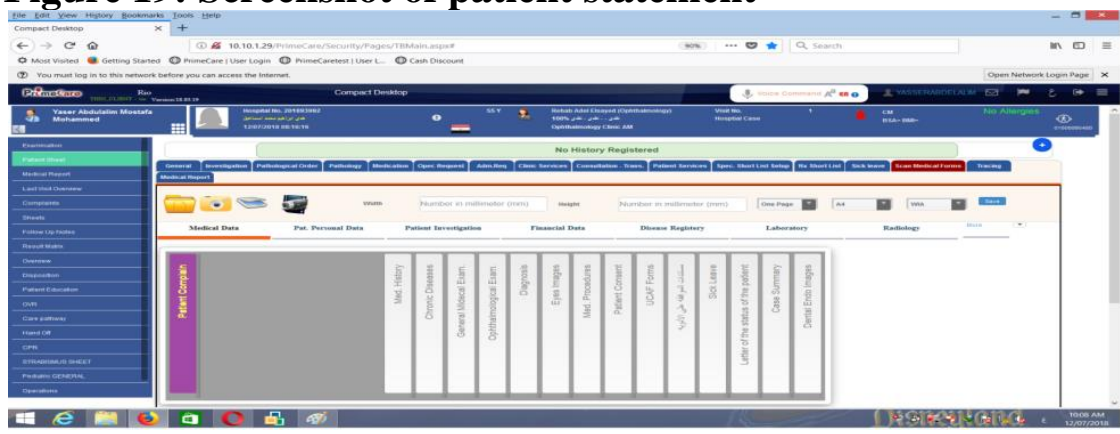

Figure 20: Screenshot of scan medical forms 


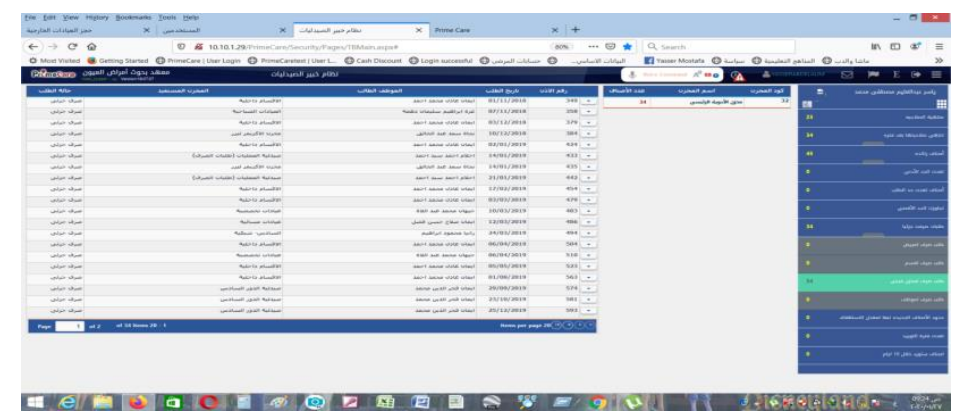

\section{Figure 21: Screenshot of Pharmacy system}

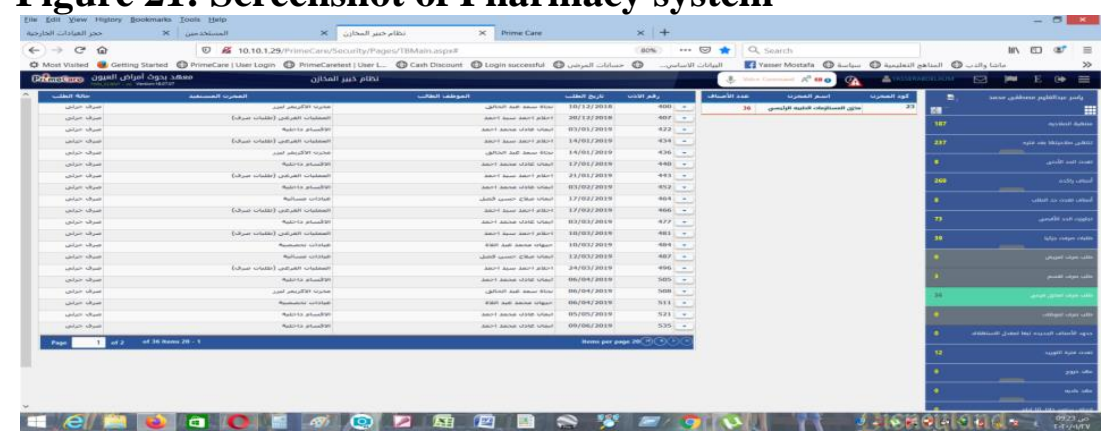

Figure 22: Screenshot ofstores and stock control system screen

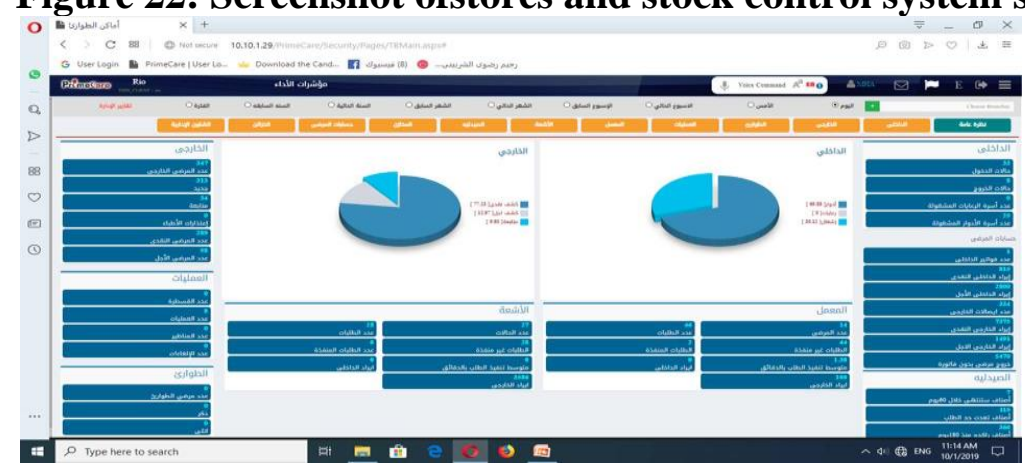

Figure 23: Screenshot of dashboard system screen

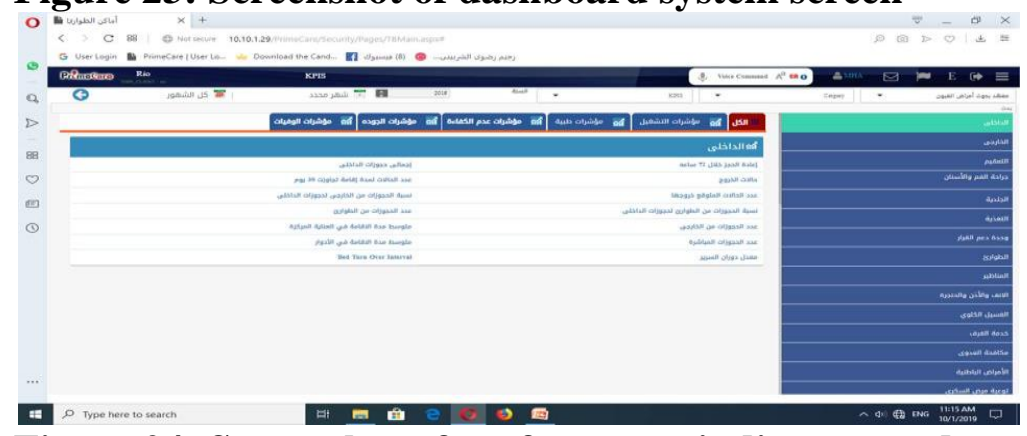

Figure 24: Screenshot of performance indicators and statistics 